\title{
The Next Frontier: Corporate America Improving Employee Productivity By Implementing Programs To Reduce Sleep Deprivation
}

Marty Meyers, University of Wisconsin at Stevens Point, USA

\begin{abstract}
This is a two-part paper that discusses sleep deprivation. The first part documents the extent of the problem with a focus on the impact of employee productivity and the second part discusses the few companies that have implemented programs to improve sleeping patterns of their employees and the wide variety of options that are available to corporate America.
\end{abstract}

Keywords: Sleep Deprivation; Employee Productivity; Chronic Drowsiness; Sleep Disorders; Nap Rooms

\section{INTRODUCTION}

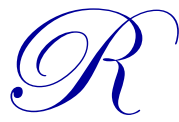

est. That's what I need is rest was an airline captain's comment to the control tower 30 minutes before crashing his airliner at a low altitude, killing the crew and all of the passengers. The Exxon Valdez oil tanker crashed in 1989 in Prince William Sound in Alaska. Thousands of barrels of crude oil spilled into the area that resulted in destructive environmental consequences and a cleanup bill of well over $\$ 1$ billion. The mate at the helm was described as being too sleepy to perform his responsibilities.

Another error took place that resulted in extensive ecological destruction when a waste-treatment plant operator at a big oil refinery fell asleep on the job and unfortunately dumped thousands of gallons of chemicals into a nearby river. In 1984, two Burlington Northern Freight trains crashed into each other in Colorado. Five crew members were killed and there was extensive damage to the trains. The National Transportation Safety Board determined that the probable cause of the crash was that the engineer and crew members from one of the trains fell asleep.

Nearly one in every three Americans report having fallen asleep at the wheel. At least one in every twenty Americans has caused an accident by falling asleep while driving and alcohol is involved in one-third of the accidents in which the driver fell asleep. There is a relationship between hours worked and the risk of falling asleep at the wheel. Sleepiness is second only to drunkenness as a cause for automobile accidents. Sleepiness and fatigue is the number one cause of heavy trucking accidents. In a major trucking firm, 75 percent of its drivers were found to have a medical condition called sleep apnea. The company physician had never heard of the disorder (Maas, 1998).

\section{Impact Of Sleep Deprivation}

According to Harvard scientists, sleep deprivation costs American companies approximately $\$ 63.2$ billion in lost productivity on an annual basis. The major reason for the loss in productivity would be employees showing up for work, but operating at a less than optimal level. About $30 \%$ of the civilian workforce does not get enough rest (Weber, 2013). Forty-three percent of Americans age 13 to 64 say they rarely or never get a good night's sleep on weeknights. Further, nearly 41 million American workers do not get enough sleep (Ramirez, 2013) 
Chronic drowsiness in the workplace can result in slower reaction times, an inability to concentrate, and difficulty remembering information over longer periods of time (Markowitz, 2011). Sleep deprivation can reduce the ability to assimilate and analyze new information. Further, sleep deprivation can reduce creativity (Maas, 1998).

Sleep deprivation usually leads to the lowering of cognitive performance. Those in residency who were on call the previous night made more mistakes in reading electrocardiograms than those who were not on call the previous night. Further, the lowering of the residents' performance after a period of 24 hours of sleep loss was comparable to the effect of blood alcohol concentration of .1\%. A level of alcohol that high is considered unacceptable for practicing medicine. Findings indicate that the effect of sleep loss of 24 to 30 hours was less for the physicians than non-physicians (Philbert, 2005). Another medical study reported increased technical errors in simulated laparoscopic surgical skills after being up all night (Eastridge, 2003).

Many studies have documented that sleep deprivation leads to medical conditions such as heart disease, strokes, obesity, diabetes, depression, anxiety, and even cancer. There is a claim about an individual who was developing diabetes; all of the signs of the disease disappeared after he successfully changed his sleeping patterns (Ramirez, 2013).

Approximately 5 million employees endure sleep disorders as a result from shift work; nearly 70 percent of have trouble falling asleep. Those working daytime jobs average one to two more hours of sleep compared to shift workers and they average three or more hours of sleep during the weekends. Reducing the shift workers' sleepiness can be helped by providing bright daylight spectrum lighting in work areas and changing shift schedules so that workers rotate no more frequently than once every three weeks, with two days off between shift changes (Maas, 1998).

\section{Companies Dealing With Sleep Deprivation}

Dr. James Maas is the author of the book, "Power Sleep: The Revolutionary Program that Prepares Your Mind for Peak Performance". He spoke at an annual executive development event and explained the science of sleeping and the impact it has on performance. With the use of technology, he demonstrated the difference between brain activity following a night of inadequate sleep compared to a night of adequate sleep. He spoke about simple lifestyle changes such as avoiding caffeine and alcohol at night, daily exercise, reducing stress levels, and creating a sleep-inducing bedroom environment (Ramirez, 2013).

Researchers at the University of California Berkeley conducted research in 2010 that demonstrated how taking a nap can improve the ability of the brain to retain information. A study in 2008 at the University of Haifa found naps speeding up the process of long-term memory consolidation. A study conducted in 2007 by the National Institute of Occupational Safety and Health concluded that a short nap might improve job satisfaction and moods (Markowitz, 2011). Another study revealed that a fifteen-minute nap can rejuvenate the body (Gould, 1995). Naps strengthen the ability to pay close attention to details and to make critical decisions (Maas, 1998).

Some American companies are offering nap rooms to their employees. A survey conducted by the Society for Human Resource Management reported that $6 \%$ of work places had nap rooms in 2011, a slight increase from the 5\% in 2010. Some companies are making energy pods available for their employees. An energy pod is a futuristic-looking white capsule where those taking a nap can recline and set timers to wake themselves up with vibrations and lights. The Energy Pod is manufactured by MetroNaps, a company headquartered in California. Google's Mountain View campus has energy pods available for their employees. Arianna Huffington has spoken in favor of napping rooms and offers, for her employees, energy pods at the Huffington Post headquarters building. The Nevada-based web retailer, Zappos, has positioned the company as a fun and dynamic place to work. One of their perks is the availability of a nap room for their employees. A Manhattan-based investment firm has supplied a comfortable couch by the trading bullpen for the employees to take power naps (Delo, 2011).

The Park Hyatt Beaver Creek Resort has launched Sound Sleep Initiatives a program targeted to hotel guests and employees. The program was developed in partnership with Nancy Rothstein, a consultant known as the sleep ambassador. The associates employed by the hotel have been trained to familiarize themselves with the sleep 
initiatives which include things like a television channel with music that enhances sleep for the guests, massage treatments, sleep-friendly foods and beverages, and oxygen canisters and humidifiers to assist with the adjustment of being in a high altitude in the Rocky Mountains (author unknown, 2013).

The Sleep Ambassador, with guest experts, teaches a six-week course called "Sleep Well and Live Well: Six Weeks to Better Sleep", through the School of Continuing and Professional Studies at New York University. One of Rothstein's suggestions is to turn off the technology at least one-half hour before bedtime because blue spectrum light emitted by smartphones, iPads, laptops, desktops, and televisions sends a signal to the brain that it is not time to go to sleep. Ms. Rothstein has conducted classes to employees of a variety of companies on a multitude of procedures to enable a more productive sleep and she found them very effective in producing better sleep patterns for the participants (Rothstein, 2013). For example, Proctor \& Gamble hired Nancy Rothstein to give a presentation at their headquarters in Cincinnati, Ohio. Part of her presentation provided an explanation on the importance of shutting off screen devices one hour before bed (Weber, 2013).

Litebook Company is a Canadian firm that manufactures light that helps regulate the body's melatonin levels. The company sells their products to The Philadelphia Flyers and Ottawa Senators to help athletes cope with the effects of jet lag, and corporations are becoming more interested in making the lights available to their employees (Weber, 2013).

\section{CONCLUSIONS}

Employers are quick to offer programs that focus on nutrition, fitness, treating alcoholism, smoking cessation, and stress management, but not for sleep deprivation. Studies do document that dealing with sleep deprivation would have an impact on employee productivity (Ramirez, 2013). The author of this paper predicts that dealing with sleep deprivation will be the next issue that corporate America attempts to tackle for dealing with employee morale, wellness, and productivity.

\section{FUTURE RESEARCH}

Future research will explore the differences in sleep deprivation between the United States and the rest of the world. Initial research reveals that there is less stress in the European and Latin American countries (Maas, 1998). A more detailed analysis will lead to a discussion on a comparison of sleep deprivation in the United States compared to the rest of the world. The research will also consider what is being done in other countries in terms of dealing with sleep deprivation.

\section{AUTHOR INFORMATION}

Marty Meyers has been a marketing professor at the University of Wisconsin-Stevens Point since 1986. Courses taught have included principles of marketing, international marketing, and buyer behavior. Special interests include marketing in Africa and improving employee productivity. Email: mmeyers@uwsp.edu.

\section{REFERENCES}

Delo, C. (2011). "Why Companies are Cozying up to Napping at Work, Fortune Management, August 18

Eastridge B., (2003) "Effect of Sleep Deprivation on the Performance of Laparoscopic Surgical Skills," American Journal of Surgery 186 (2) 169-174.

Friedman, R. (1971). “The Intern and Sleep Loss,” New England Journal of Medicine, 285 201-203.

Gould, M. (1995). "Power Napping," Nation's Business, 83 (2) 65.

Maas, J. B. (1998). Power Sleep, The Evolutionary Program That Prepares Your Mind for Peak Performance, New York, Random House.

Markowitz, E. (2011). “Should Your Employees Take Naps?' Inc. August 12.

Philbert, I. (2005). "Sleep Loss and Performance in Residents and Non-physicians: a Meta-analytic Examination." Sleep 28 (11) 1393-1401.

Ramirez, J. (2013). "Waking Up the Workplace” Human Resource Executive, May 7. 
Rothstein, N. (2013). “6 Tips for Better Sleep This Summer, Special to CNN, June 6.

Unknown author. (2013). Park Hyatt Beaver Creek Resort and Spa Partners with Nancy Rothstein, The Sleep Ambassador, to Introduce New Sound Sleep Initiatives, www.hotelinteractive.com February 22.

Weber, L. (2013). “Go Ahead, Hit the Snooze Button,” Wall Street Journal, January 23. 